\title{
Nanobiosensor for Detection and Quantification of DNA Sequences in Degraded Mixed Meats
}

\author{
M. E. Ali, ${ }^{1}$ U. Hashim, ${ }^{1}$ S. Mustafa, ${ }^{2}$ Y. B. Che Man, ${ }^{2}$ M. H. M. Yusop, ${ }^{2}$ M. Kashif, ${ }^{1}$ \\ Th. S. Dhahi, ${ }^{1}$ M. F. Bari, ${ }^{3}$ M. A. Hakim, ${ }^{4}$ and M. A. Latif ${ }^{5}$ \\ ${ }^{1}$ Institute of Nano Electronic Engineering (INNE), Universiti Malaysia Perlis, 01000 Kangar, Perlis, Malaysia \\ ${ }^{2}$ Halal Products Research Institute, Universiti Putra Malaysia, 43400 UPM Serdang, Selangor, Malaysia \\ ${ }^{3}$ School of Materials Engineering, Universiti Malaysia Perlis, 01000 Kangar, Perlis, Malaysia \\ ${ }^{4}$ Institute of Tropical Agriculture, Universiti Putra Malaysia, 43400 UPM Serdang, Selangor, Malaysia \\ ${ }^{5}$ Department of Crop Science, Faculty of Agriculture, Universiti Putra Malaysia, 43400 UPM Serdang, Selangor, Malaysia
}

Correspondence should be addressed to U. Hashim, uda@unimap.edu.my

Received 9 November 2010; Accepted 10 April 2011

Academic Editor: Claude Estournes

Copyright ( $\odot 2011$ M. E. Ali et al. This is an open access article distributed under the Creative Commons Attribution License, which permits unrestricted use, distribution, and reproduction in any medium, provided the original work is properly cited.

\begin{abstract}
A novel class of nanobiosensor was developed by integrating a 27-nucleotide AluI fragment of swine cytochrome b (cytb) gene to a 3-nm diameter citrate-tannate coated gold nanoparticle (GNP). The biosensor detected $0.5 \%$ and $1 \%$ pork in raw and 2.5 $\mathrm{h}$ autoclaved pork-beef binary admixtures in a single step without any separation or washing. The hybridization kinetics of the hybrid sensor was studied with synthetic and AluI digested real pork targets from moderate to extreme target concentrations and a sigmoidal relationship was found. Using the kinetic curve, a convenient method for quantifying and counting target DNA copy number was developed. The accuracy of the method was over $90 \%$ and $80 \%$ for raw and autoclaved pork-beef binary admixtures in the range of $5-100 \%$ pork adulteration. The biosensor probe identified a target DNA sequence that was several-folds shorter than a typical PCR-template. This offered the detection and quantitation of potential targets in highly processed or degraded samples where PCR amplification was not possible due to template crisis. The assay was a viable alternative approach of qPCR for detecting, quantifying and counting copy number of shorter size DNA sequences to address a wide ranging biological problem in food industry, diagnostic laboratories and forensic medicine.
\end{abstract}

\section{Introduction}

Hybrid biomaterials composed of functionalized nanoparticles, covalently linked to biomolecules such as peptides, proteins, and polynucleotides, are especially interesting for their size-dependent properties and dimensional similarities to biomacromolecules [1-8]. These nanobioconjugates are potential agents for multiplexed bioassays $[9,10]$, materials synthesis $[1,11-13]$, ultrasensitive optical detection and imaging [14-16], in vivo magnetic resonance imaging (MRI) $[17,18]$, long-circulating carriers for targeted drug release [19], and structural scaffold for tissue engineering [20].

Nanoscaffolding and nanoquenching properties of thiolcapped gold nanocrystals (GNCs), covalently linked to fluorophore-lebeled oligonucleotide through metal-sulfur bond, were extensively studied for decades to detect specific se- quences and single-nucleotide mismatches [1-3,21,22]. Unfortunately, such studies were limited to the laboratory level model experiments with synthetic oligo-targets. No studies so far practically explored the sequence and mismatch detecting power of the fluorophore-labeled-oligo-nanoparticle conjugates in heterogeneous biological samples. Hybridization kinetics of such nanobio-conjugates is also remained unknown.

In this paper, we have structurally and functionally integrated a 3-nm diameter citrate-tannate-coated gold nanocrystal to fabricate a novel class of species-specific nanobiosensor to determine pork adulteration in raw as well as processed mixed meats. Several reports have highlighted the significance and importance of species determination in meat and meat products for health and religious concern to certain food ingredients as well as promotion of fair-trade with 
proper labeling of processed food $[23,24]$. Species-specific PCR-cum-electrophoresis [25, 26], PCR-RFLP [27, 28], TaqMan real-time PCR [29], and DNA barcoding [23, 30-32] are the predominant DNA-based techniques currently used in species analysis. However, all of these methods involve PCR amplification of target DNA that is typically more than hundred base-pair long [25-30]. Several studies implicated that longer DNA targets are broken down to small fragments during extensive food processing causing failure of PCRbased identification methods [23, 26, 28, 31]. Moreover, the recent report on frequent artifacts on real-time PCR results [33] has raised the questions of validity of the existing DNAbased methods in the analysis of highly processed meat products.

In this paper, we have targeted a 27-bp AluI fragment of porcine mitochondrial cytochrome b (cytb) gene to construct porcine-specific hybrid nanobiosensor probe that was able to detect pork in heterogeneous autoclaved meat products in a single step eliminating the need of washing or separation steps. The legitimacy of using cytb gene lies on its high rate of evolution and abundant copy number [32]. Mitochondrial genes are also protected against degradation by the protective shape and size of mitochondrion. The core of the assay was a 3-nm citrate-tannate-coated gold nanocrystal that was structurally and functionally integrated to shorter-size species-specific synthetic oligonucleotides (oligos). Citrate-tannate-coated gold nanoparticles are highly stable and easy to prepare in convenient sizes [34, 35]. The oligo was labeled with an alkanethiol at one end and a fluorescent dye, tetramethyl-rhodamine (TMR), at the other. Upon binding to nanocrystal surface via sulfur-gold bond, the oligo was self-organized into an arch-like closed conformation in which the fluorescence was almost-completely sucked by the nanoparticle through nonradiative energy transfer. Upon target binding, the constrained structure turned into a straight conformation separating fluorophore from the nanoparticles surface. This change in structural conformation generated a fluorescence signal that was very sensitive and specific to the target DNA hybridization. Our approach directly used AluI digested total DNA extracted from raw and heat processed mixed meats avoiding any further purification steps. The limit of detection (LOD) of the assay was found $58.6 \mathrm{pM}$ with synthetic target and $230 \mu \mathrm{g} / \mathrm{L}$ with total DNA without any ambiguity. The study of hybridization kinetics revealed sigmoidal relation with emitted fluorescence and target DNA concentration. Using the kinetic curve, a convenient method for quantification as well as counting copy number of target DNA in unknown mixed biological samples was developed.

\section{Materials and Methods}

2.1. Design of Porcine- and Bovine-Specific Oligo-Probes. Sus scrofa (porcine) and Bos taurus (bovine) cytb genes (GenBank: HM010474 \& EU807948.1) were retrieved from NCBI data base and subjected to AluI digestion by NEB Cutter Version 2.0 and (http://tools.neb.com/NEBcutter2/) and REBASE (http://rebase.neb.com/rebase/rebase.html) softwares. A 27-bp AluI fragment of porcine cytb (428-454 bp) revealed high degree of interspecies polymorphism by BLAST (basic local alignment search tools) (http://www.ncbi.nlm.nih.gov/) analysis against nonredundant nucleotide collection as well as ClustalW (http://www.ebi.ac.uk/Tools/ClustalW/) alignment analysis. The oligo-probes were purchased from Integrated DNA Technologies, USA, with 6-carboxy tetramethyl-rhodamine (TMR) and hexamethyl-thiol at the $5^{\prime}-\& 3^{\prime}$-ends of the complementary fragments with inserted poy-A $\left(\mathrm{A}_{6}\right)$ spacers as shown in Table 1. The synthetic targets (complementary, noncomplementary, and single-mismatch) were purchased from the 1st Base, Selangor, Malaysia.

2.2. Synthesis of Colloidal Gold Nanoparticles. Small gold nanoparticles ((GNPs) were prepared with a little modification of the protocol described elsewhere [34]. Firstly, $1 \mathrm{~mL}$ of $1 \%$ chloroauric acid $\left(\mathrm{HAuCl}_{4}\right)$ is added to $80 \mathrm{~mL}$ water to make solution A. Secondly, $5 \mathrm{~mL}$ of $1 \%$ trisodium citrate. $2 \mathrm{H}_{2} \mathrm{O}, 6 \mathrm{~mL}$ of $1 \%$ tannic acid, $6 \mathrm{~mL}$ of $25 \mathrm{mM}$ potassium carbonate, and $3 \mathrm{~mL}$ water were mixed to make solution $\mathrm{B}$. Solutions $\mathrm{A}$ and $\mathrm{B}$ were brought to $60^{\circ} \mathrm{C}$ in a water bath and mixed while stirring vigorously. After $30 \mathrm{~min}$, the mixture was brought to $95^{\circ} \mathrm{C}$ and then cooled on an ice bath. The colloidal sol was characterized by Hitachi 7100 transmission electron microscope and PerkinElmer Lamda 25 UV-vis spectroscopy. The average size of the particles was assigned $3 \pm 0.2 \mathrm{~nm}$ in diameter by measuring 500 particles (Figure S1 in Supplementary Material available online at doi: 10.1155/2011/781098). The approximate number and concentration of the particles were calculated according to Heiss et al. [35] and Nanopartz's technical note [36] and were found to be $2.01 \times 10^{11} \mathrm{NPS} / \mu \mathrm{L}$ and $335 \mathrm{nM}$. All chemicals used in this section were from Sigma Aldrich and were used without further purification. All glasswares used in the preparation were cleaned with piranha solution and ovendried. All solutions were made in $18.2 \Omega$ Millipore water (Sartorius).

2.3. Preparation of Hybrid Nanobioprobe. To construct swine-specific conjugated nanobioprobe, custom-made porcine oligo-probes (Table 1) were incubated overnight at $20^{\circ} \mathrm{C}$ in a shaking water bath with citrate-tannate-coated GNPs at a ratio of 3 oligos per particles to ensure that each particle was conjugated to at least one oligo molecule [1]. To improve the stability and consequent hybridization efficiency, the oligo-particle conjugates were aged in $0.1 \mathrm{M}$ $\mathrm{NaCl}$ in $10 \mathrm{mM}$ PBS ( $\mathrm{pH} 7.4$ ) for 16-h according to Mirkin et al. $[11,37]$. The nanoparticle probes were separated from unbound oligos by three times centrifugation at 50,000 rpm for $25 \mathrm{~min}$. The final products were loose red pellets which were reconstituted in $10 \mathrm{mM}$ PBS. The number of oligo molecules per particle was determined by 2-mercaptoethanol digestion according to the procedure described by Maxwell and coworkers [1].

2.4. Specificity and Sensitivity Tests. An aliquot of the purified nanoparticle probes was diluted to $10 \mathrm{nM}$ with hybridization 
TABLE 1: Probe and target oligo sequences used.

\begin{tabular}{lc}
\hline Name & Sequences $\left(5^{\prime} \rightarrow 3^{\prime}\right)$ \\
\hline Porcine-probe (thiolated) & TMR-A $_{6}-$ CTG ATA GTA GAT TTG TGA TGA CCG TAG-A $_{6}-\left(\mathrm{CH}_{2}\right)_{6}-\mathrm{SH}$ \\
Porcine-probe (nonthiolated) & TMR-A $_{6}-$ CTG ATA GTA GAT TTG TGA TGA CCG TAG- A \\
Porcine-target (complementary) & CTA CGG TCA TCA CAA ATC TAC TAT CAG \\
Porcine-target (noncomplementary) & ACG TAA CTG CTG TGG CCA GGT CGC TGA \\
Porcine-target (single mismatch) & CTA CGG TCA TCA CAA ATT TAC TAT CAG \\
\hline
\end{tabular}

Single mismatch base is shown in underlined bold letter.

buffer (90 mM KCl, $10 \mathrm{mM}$ Tris, $\mathrm{pH}$ 8.0). To determine specificity, the probes were incubated with a 4-fold excess $(60 \mathrm{nM})$ of complementary, noncomplementary, and singlemismatch targets (Table 1 ) at $70^{\circ} \mathrm{C}$ for 5 min to allow strand separation and then at $40^{\circ} \mathrm{C}$ for $30-60 \mathrm{~min}$ to allow hybridization. To determine the limit of detection (LOD), the 8-fold excess of complementary targets were serially diluted (as shown in Table S1 in Supplementary Material) from $120 \mathrm{nM}$ to $3.66 \mathrm{pM}$ with hybridization buffer and were incubated for 60-min with $10 \mathrm{nM}$ nanoparticle probes.

2.5. Specificity and Sensitivity Tests in Mixed Biological Samples. Separate aliquots of $100 \mathrm{~g}$ pork-beef binary admixtures were prepared in a ratio of $100: 0,50: 50,25: 75,10: 90$, $5: 95,1: 99,0.5: 99.5,0.1: 99.9$, and $0: 100$ fresh pork and beef. The mixtures were autoclaved at $120^{\circ} \mathrm{C}$ for $2.5-\mathrm{h}$, and DNAs were extracted from $100 \mathrm{mg}$ sample in triplicates using MasterPure DNA Purification Kit (Epicentre Biotechnologies, Madison, USA) as per the protocol optimized and supplied by the manufacturing company. The purity and concentration of extracted DNA samples were checked by Eppendorf UV-vis Biophotometer (Eppendorf, Germany) and the following formulas were used to calculate purity and concentration:

$$
\begin{aligned}
& \text { DNA Purity }\left(\frac{A_{260}}{A_{280}}\right): \\
& \frac{\left(A_{260} \text { Reading }-A_{320} \text { Reading }\right)}{\left(A_{280} \text { Reading }-A_{320} \text { Reading }\right)}
\end{aligned}
$$

DNA concentration $(\mu \mathrm{g} / \mathrm{mL})$ :

$$
\begin{gathered}
\left(\mathrm{A}_{260} \text { Reading }-\mathrm{A}_{320} \text { Reading }\right) \\
\times \text { Dilution Factor } \times 50
\end{gathered}
$$

(http://www.promega.com/enotes/faqspeak/fq0059.htm).

The purity $\left(\mathrm{A}_{260} / \mathrm{A}_{280}\right)$ of all DNA samples used in subsequent experiments was 1.95-2.0.

The extracted total DNA $(500 \mu \mathrm{g} / \mathrm{mL})$ was digested with AluI (New England Biolabs, UK) restriction enzymes. The digestions were performed in a total volume of $1 \mathrm{~mL}$ containing $600 \mu \mathrm{L}$ of total DNA, $300 \mathrm{U}$ of restriction enzymes, and $100 \mu \mathrm{L}$ of digestion buffer (New England Biolabs, UK) for 8 -h at $37^{\circ} \mathrm{C}$ in a shaking water bath. The final volume was adjusted with $18.2 \Omega$ Millipore water. The digestions were confirmed by electrophoresis on 3\% agarose gel with ethidium bromide staining.
The hybridization reaction was performed in a total volume of $2.5 \mathrm{~mL}$ in triplicates with $10 \mathrm{nM}$ probes and $60 \mu \mathrm{g} / \mathrm{mL}$ AluI digested mixed DNA according to the procedure described in Section 2.4. For the study of hybridization kinetics and generation of standard curve, $10 \mathrm{nM}$ probes and various concentrations (shown in Table S2 in Supplementary Material) of AluI digested raw-pork DNA were incubated in a $2.5 \mathrm{~mL}$ reaction volume at $40^{\circ} \mathrm{C}$ for $60 \mathrm{~min}$. Concentration adjustment was performed with hybridigestion buffer.

2.6. Fluorescence Measurement. The emission spectra were collected in a $10-\mathrm{mm}$ cuvette with $2-\mathrm{mL}$ volume in PerkinElmer LS55 fluorescence spectrometer with excitation at 545-nm. Each spectrum was an average of 5-scan at the scan speed of $200 \mathrm{~nm} / \mathrm{min}$ with $5-\mathrm{nm}$ slit width. The background was subtracted by replacing sample with $2: 1$ ratio of $10 \mathrm{mM}$ PBS and hybridization buffer. For the determination of LOD, a series of fluorescence spectra were obtained in triplicates and average fluorescence intensity at 579-nm was plotted as a function of target concentration.

2.7. PCR Amplification. In order to test the applicability of the PCR assay in 2.5-h autoclaved mixed meat, porcinespecific PCR assay was performed with primers reported by Rodríguez et al. [29]. The $25 \mu \mathrm{L}$ volume of final reaction mixture was composed of $1 \mathrm{x}$ superhot PCR mastermix (Bioron, GmbH, Germany), $10 \mathrm{ng}$ DNA, $300 \mathrm{nM}$ of forward primer, and $900 \mathrm{nM}$ of reverse primer. The PCR program (Eppendorf, Germany) was set with a initial preheating at $95^{\circ} \mathrm{C}$ for $10 \mathrm{~min}$ and 35 cycles of amplification composed of $30 \mathrm{~s}$ denaturation at $95^{\circ} \mathrm{C}, 30 \mathrm{~s}$ annealing at $50^{\circ} \mathrm{C}$, and $30 \mathrm{~s}$ extension at $72^{\circ} \mathrm{C}$ followed by final extension at $72^{\circ} \mathrm{C}$ for $5 \mathrm{~min}$. PCR reaction mixture without template DNA and replacement with sterile water was used as negative template control (NTC) to ensure the purity of the PCR reaction mixture from contaminating DNA. The PCR products were separated by electrophoresis on $1.5 \%$ agarose gel and visualized by ethidium bromide staining under UV-lamp (Alpha Innotech, USA).

\section{Results and Discussion}

3.1. Detection and Quantitation Principle. It has been shown that hybrid materials composed of single-stranded DNA (ssDNA) covalently linked to a small gold nanoparticle (2$3 \mathrm{~nm}$ in diameter) via sulfur-gold bond at one extremity and a fluorescent dye to the other, can assume two distinct 
conformations: (1) a constrained conformation (stem-loop or arch-like structure in closed state) that appears before target binding and (2) a rod-like structure (straight conformation in open state) that appears after target binding. In the constrained structure, the fluorophore, and the GNP are held in close proximity, and the fluorescence is quenched by nonradiative energy transfer from dye to the metal. On the other hand, in the rod-like structure the fluorophore is far apart $(>2 \mathrm{~nm})$ from the metal particle and emit fluorescence [1-3]. We assume that the degree of fluorescence emission depends on the degree of target binding. Thus, the maximum fluorescence is observed when the probe is saturated with the targets and the base-line fluorescence is obtained in the absence of any targets. Based on this assumption, a standard curve can be generated with known concentrations of probes and targets, and the concentration of the unknown can be obtained by plugging the observed fluorescence in the standard curve. The concentration of unknown sample should also be mathematically calculated from the following equation within a certain limit: $C_{2}=$ $C_{1} I_{2} / I_{1}$, where $C_{2}=$ concentration of unknown target below the saturation limit, $I_{2}=$ observed fluorescence of the unknown, $C_{1}=$ concentration of standard target below the limit of saturation, and $I_{1}=$ fluorescence intensity of the standard. The calculated concentrations of the unknown are found to be fairly accurate if closely matched values of the standard are taken from the standard curve during calculation. The operating principles of the nanoparticle probes are schematically shown in Figure 1.

3.2. Preparation of Species-Specific Nanobiosensor. The species-specific hybrid nanobiosensors were prepared by immobilizing fluorescently labeled species-specific oligonucleotides (oligos) onto citrate-tannate-coated small gold nanocrystals (3-nm in diameter). A 27-bp AluI-fragment of porcine cytb genes that demonstrated high degree of interspecies polymorphism by ClustalW alignment analysis as well as NCBI blast analysis was selected as porcine-specific marker. A hexyl-A $\left(\mathrm{A}_{6}\right)$ spacer was inserted at the two ends of the complementary sequences of these fragments to eliminate steric hindrance $[1,38]$. Poly-A linker is also reported to produce significant contributions in the formation and stability of DNA-gold complexes as adenine is known to have the highest affinity for gold among the four bases of DNA [38]. At the $3^{\prime}$-end of the oligo-probe, a thiol (-SH) group spaced by a hexamethyl $\left[\left(-\mathrm{CH}_{2}\right)_{6}\right]$ spacer was added to tether the oligo onto the nanocrystal surface through relatively stable sulfur-gold bond [1, 37-40]. At 5'-end 6-carboxy tetramethyl rhodamine (TMR) was added due to its reported stability and sensitivity to gold nanoparticles $[1,3]$.

3.3. Characterization of Hybrid Nanobioprobe. The UV-vis spectra of oligo-bound GNPs showed a peak at $350 \mathrm{~nm}$ and a shoulder at $530 \mathrm{~nm}$ before purification (green curve in Figure S2 in Supplementary Material), exhibiting characteristic features of tannic acid coated GNPs [41]. Three-nm-GNPs produced by other methods demonstrate a pronounced peak at $515 \mathrm{~nm}$ [37]. However, this peak was not resolved due to the strong absorbance of tannic acid at this absorption window [41]. The strong peak at $350 \mathrm{~nm}$ can be assigned to the reduction mixture of citrate and tannate as they produced stronger peak (blue curve) at this region when GNPs were removed by centrifugation [41]. Oligo, coated with alkanethiol and tetramethyl rhodamine (TMR) produced a strong peak at $560 \mathrm{~nm}$ and a shoulder at $525 \mathrm{~nm}$ (pink curve: Figure S2 in Supplementary Material). Due to lack of available data in the literature, we could not compare UV-vis spectra of thiol-tagged TMR-oligo. However, it is well documented that excitation wavelength of TMR is near 550 [1]. Therefore, the $560 \mathrm{~nm}$ absorption peak may be assigned to TMR and 525 shoulder to thiol-group. Excess tannic acid and unbound oligo-TMR (if any) were removed by centrifugation. However, the purified thiol-bound GNPs still contained tannic acid on its surfaces as an in-built trait. However, the contribution of tannic acid in absorption was reduced and the contributions of TMR and alkanethiol increased by purification treatment. As a result, a collective integrated strong peak contributed by tannate-coated GNPs, alkanethiol, and TMR was appeared at $540 \mathrm{~nm}$ region.

3.4. Quenching Mechanism. Fluorescence profile of alkanethiolated (5'-TMR-A 6 -CTG ATA GTA GAT TTG TGA TGA CCG TAG- $\left.\mathrm{A}_{6}-\left(\mathrm{CH}_{2}\right)_{6}-\mathrm{SH}-3^{\prime}\right)$ and nonthiolated (5'-TMR$\mathrm{A}_{6}$-CTG ATA GTA GAT TTG TGA TGA CCG TAG- $\mathrm{A}_{6}-$ $3^{\prime}$ ) porcine oligo-TMR probes are shown in Figure 2. Both thiolated and nonthiolated oligo-TMR produced similar emission spectra $(\lambda \mathrm{em} 585 \mathrm{~nm})$ in water in the absence of any quencher (green and red curves). However, in the presence of 2.5-fold molar excess of GNPs, $\lambda$ em of thiolated TMR-labeled oligo was blue shifted to $579 \pm 1 \mathrm{~nm}$. While the $\lambda$ em of nonthiolated-oligo-TMR retained its position, both of them were approximately $60 \%$ quenched. According to Maxwell et al. [1], this type of fluorescence quenching is due to collision between fluorescent dye and metal nanoparticles and called dynamic quenching. During this collision, thiolated-oligoTMR probably produced stable gold-sulfur (Au-S-) bond with gold particles, and emission peak was blue-shifted. Maxwell et al. [1] also observed different fluorescence spectra of thiol-anchored and nonthiolated oligos. However, we did not find any significant difference in spectral character in the absence of nanogold crystals. The change in spectral features of thiol-anchored oligo-TMR was most likely caused by the formation of stable gold-thiol bond. This gold-thiol bonding was most likely the initial step toward the formation of arch-like structures that are shown in Figure 1. Archlike conformation brings total loss of fluorescence by nonradiative energy transfer from fluorophore to metal particle $[1,3]$. However, here only $60 \%$ fluorescence quenching was observed. We attributed to the formation of an intermediate conformation towards the formation of complete constrained structure. Nonthiolated oligo oscillated onto the nanoparticle surfaces during the collision phase and could not produce arch-like or any intermediate structures. Quenching resulted from the frictions or adsorption of fluorophores to nanoparticles. 

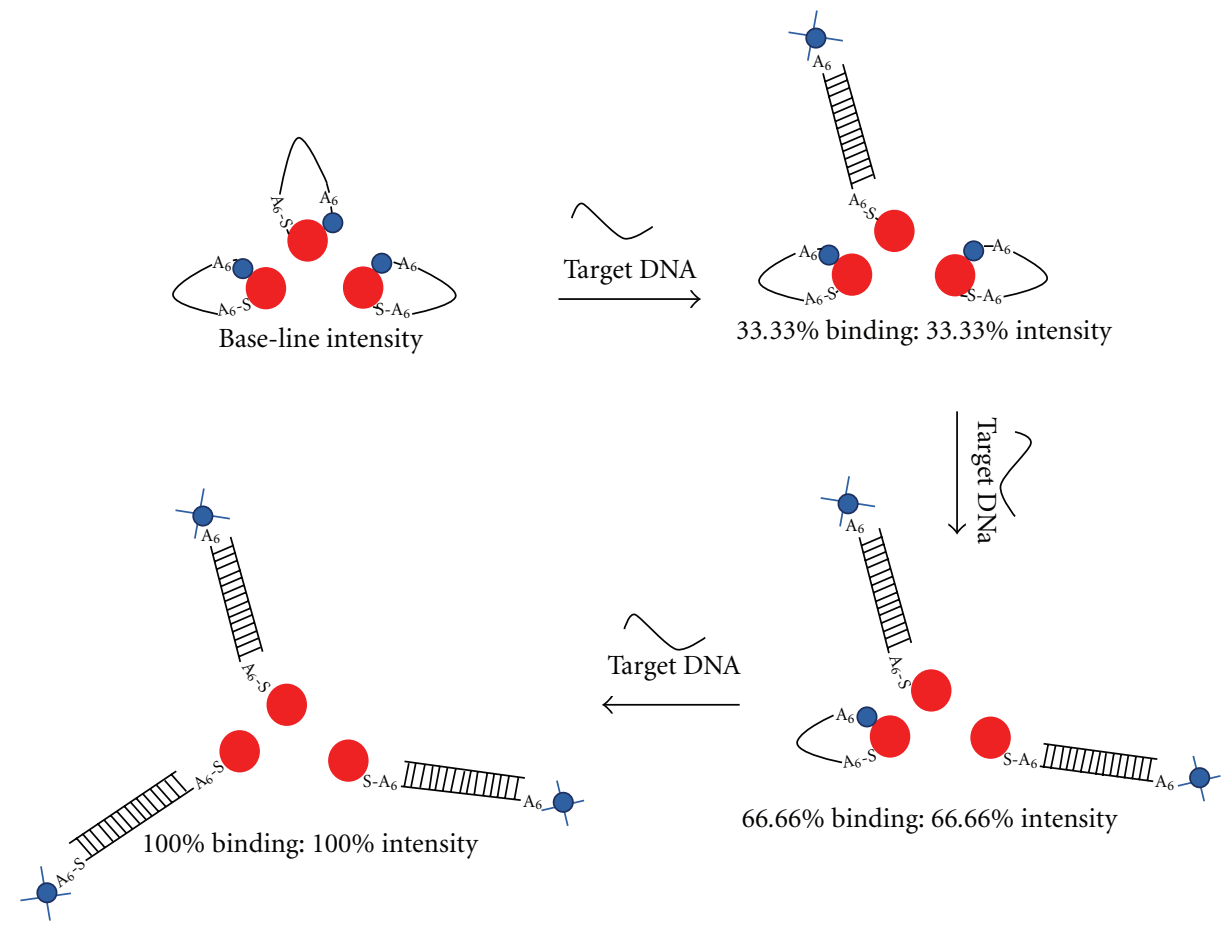

FIGURE 1: Schematic presentation of quantification and operating principles of swine nanobiosensor. Three oligonucleotides probes flanked by a hexyl-A spacer at both sides and alkanethiol cap at one-end and fluorophore at the other are shown to self-organize in a constrained archlike structure where the fluorophore is quenched by the nanoparticle in the absence of any complementary targets. Upon target binding, the closed structure is opened into a rod-like conformation separating the fluorescent dye from the nanoparticle to allow fluorescence emission. The degree of fluorescence emission is shown to proportionate the degree of target hybridization, constituting the basis of quantitation. Gold nanoparticles and fluorophores are demonstrated by red and blue spheres. ssDNA and dsDNA are represented by single and cross-linked double lines.

Different quenching properties of oligo-tagged and free fluorophores with colloidal gold and silver particles were observed in previous studies $[1,42]$. Most fluorescent dyes spontaneously adsorb on gold and silver surfaces. However, the negative charges of oligos inhibit fluorophore adsorption onto the negatively charged GNPs when the fluorescent dyes are covalently linked to the oligos. Small amount (1-10 $\mu \mathrm{M})$ of divalent ions $\left(\mathrm{Mg}^{++}\right)$neutralizes the negative charges on the phosphate backbones of oligos to allow static adsorption of fluorophores onto the negatively charged metal nanoparticles [1]. In the current assay $98-99.99 \%$ quenching was found with thiolated DNA and $100 \%$ with nonthiolated one, demonstrating that arch-like structures do not allow $100 \%$ static quenching through nonradiative energy transfer. Maxwell et al. also got strong background fluorescence with thiolated-DNA nanoparticle probes and they referred it to particle aggregation or free/unquenched oligos. According to our experiences, thiol-capped gold nanoparticle probes are less prone to aggregation and in the current assay 2.5fold molar excess of nanoparticles were used to eliminate the existence of free-oligos. Whatever may be the causes of relatively high base-line fluorescence, the arch-like conformation of thiolated nanobioprobe offered better hybridization specificity that cannot be achieved with nonthiolated counterparts $[1,3]$.
3.5. Species Specificity of the Prepared Nanobiosensor. The fluorescence spectra of $10 \mathrm{nM}$ porcine nanobiosensor probes with 4-fold molar excess $(60 \mathrm{nM})$ of complementary (red curve: top one), single-mismatch (green curve: 2 nd from the top), and noncomplementary targets (pink curve: 3 rd from the top) are shown in Figure 3. While the noncomplementary targets produced no effect on fluorescence emission, single-mismatch targets reduced $65-70 \%$ fluorescence of the perfectly match targets, demonstrating that the fabricated nanobiosensors was highly specific in discriminating against the noncomplementary and single-mismatch sequences. Maxwell et al. achieved 55\% quenching with $2.5 \mathrm{~nm}$ gold nanoparticle probes where gold nanoparticles were produced by sodium borohydride reduction [1]. Dubertret et al. achieved $75 \%$ reduction in fluorescence with molecular beacon and $1.4 \mathrm{~nm}$ gold nanocrystals [3]. According to the latter group, low ionic strength hybridization buffer $(90 \mathrm{mM} \mathrm{KCl}$, $10 \mathrm{mM}$ Tris, $\mathrm{pH}$ 8.0) more precisely differentiate perfectly matched and mismatched sequences at ambient temperature. Although the latter group achieved higher sensitivity, the gold particles they used were too small and unstable above $50^{\circ} \mathrm{C}$. Using relatively more stable citrate-tannate-coated GNPs with relatively large diameter $[36,41,43]$ as well as low ionic strength hybridization buffer [3], we achieved specificity which was higher than Maxwell et al. [1] and close to Dubertret et al. [3]. 


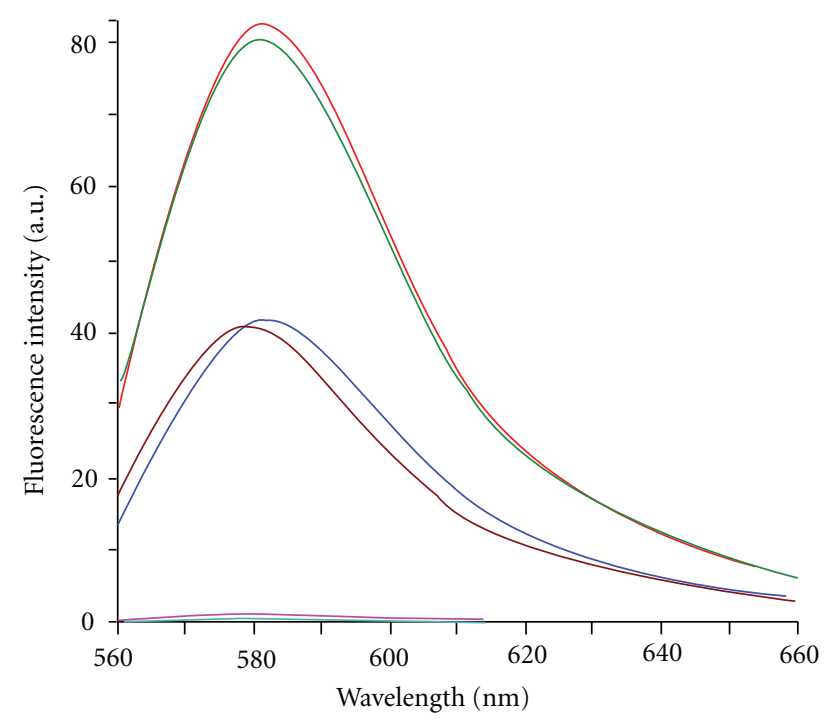

FIGURE 2: Emission spectra of $15 \mathrm{nM}$ thiolated \& nonthiolated oligo-TMR conjugates (copy number: $9.01 \times 10^{12} / \mathrm{mL}$ ) are sequentially shown under the following conditions: without any quencher (green \& red curves); with $37.5 \mathrm{nM}$ gold nanoparticles $(2.25 \times$ $\left.10^{13} \mathrm{NPS} / \mathrm{mL}\right)(60 \%$ \& $57 \%$ dynamically quenched: brown \& blue curves) and with $37.5 \mathrm{nM}$ gold nanoparticles plus $10 \mu \mathrm{M} \mathrm{MgCl}_{2}$ (99\% \& 100\% statically quenched: pink \& green curves). Different emission peaks of gold-quenched thiolated \& nonthiolated oligoTMR conjugates are noted with brown \& blue curves with emission peaks $579 \mathrm{~nm}$ and $585 \mathrm{~nm}$, respectively.

3.6. Pork Detection in Mixed Biological Samples. The fluorescence spectra of AluI digested raw and 2.5-h autoclaved porkbeef binary admixtures in various percentages are shown in Figures 4 and 5. The swine-specific biosensor probe clearly detected $0.5 \%$ (pink curves: 7 th from the top in Figure 4) and 1\% (sky-blue curves: 6th from the top in Figure 5) in the raw and extensively cooked pork-beef mixtures. This clearly reflected the high sensitivity and specificity of hybrid nanoparticle conjugates and the extraordinary stability of the target DNA under prolonged heat and pressure processing. Rodríguez et al. [29] detected $0.5 \%$ pork in pork-beef binary admixtures of raw and 20-min autoclaved meats by TaqMan real-time PCR. They used $411 \mathrm{bp}$ fragment of mitochondrial $12 \mathrm{~S}$ ribosomal RNA gene as amplification template. To test the validity of their PCR assay, we amplified the $411 \mathrm{bp}$ fragment of mitochondrial $12 \mathrm{~S}$ ribosomal gene extracted from pure raw pork as well as 2.5 -h autoclaved pork-beef admixtures using the porcine-specific primers developed by Rodríguez and coworkers [29]. The gel images of the PCR products are shown in Figure S3 in Supplementary Material. Clear band of specified PCR product was found from raw pork (lane 1), and very faint band was observed from 100\% pork autoclaved for $2.5 \mathrm{~h}$ (lane 2). No bands were visualized from $50-0.1 \%$ autoclaved pork (lanes 3-9), clearly showing the extensive degradation of template DNA by autoclaving treatment. It was thus clearly reflected that Rodriguez PCR assay was not valid to authenticate pork in extensively processed meat samples where degradation of longer DNA targets was obvious.

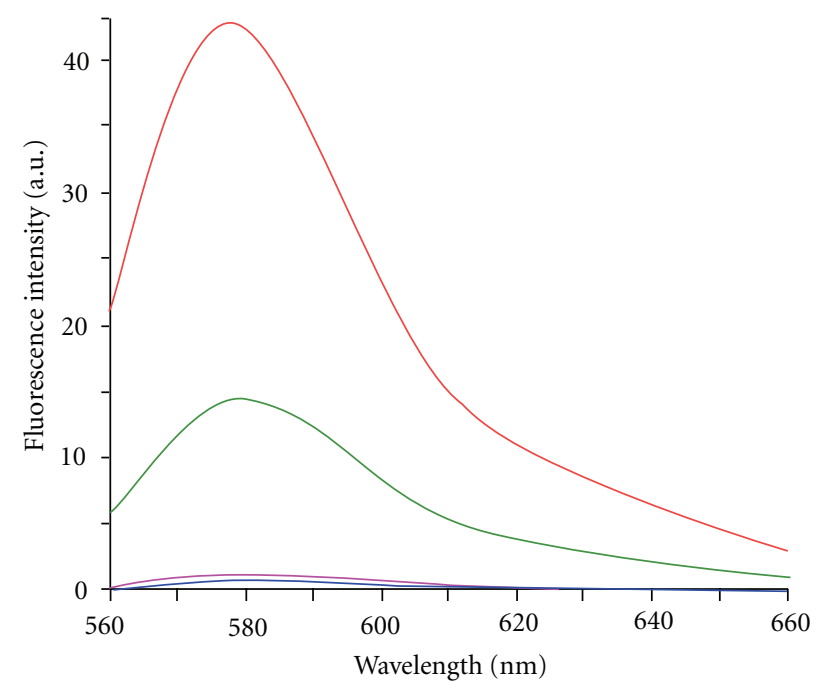

Figure 3: Detection of specific DNA sequences and single nucleotide mismatches using porcine-specific nanobiosensor probes $(10 \mathrm{nM})$. From top to bottom are 4 -folds excess (in terms of copy number) $(60 \mathrm{nM})$ perfectly complementary (red curve), single nucleotide mismatch (green curve), and noncomplementary targets (pink curve). The emission spectrum of free nanobiosensor probe $(10 \mathrm{nM})$ is shown in blue curve.

The insistently growing evidence of being broken down of longer DNA fragments by prolong heat and pressure processing $[26,31]$ strongly supported our findings. Arslan et al. studied the effects of various cooking methods such as boiling, autoclaving, roasting, and pan frying on beefspecific PCR assay [26]. They detected $271 \mathrm{bp} \mathrm{PCR} \mathrm{products}$ after boiling beef for $230 \mathrm{~min}$ at $97.5^{\circ} \mathrm{C}$. Matsunaga et al. [31] detected 157, 227, 274, 331, and 398 bp PCR products from heat-treated meat of various species at $120^{\circ} \mathrm{C}$ for $30 \mathrm{~min}$. However, they could not identified 439 bp PCR product from horse meat cooked under the same conditions. This was probably due to the degradation of relatively longer (439 bp) horse DNA during cooking [31]. On the other hand, Arslan et al. observed $271 \mathrm{bp}$ PCR product after autoclaving the beef at $120^{\circ} \mathrm{C}$ for $90 \mathrm{~min}$ [26]. These studies clearly demonstrated the great role of small-size DNA targets in the increasing stability of target DNA and validity of DNA-based identification methods in processed food. The current assay identified $1 \%$ pork using 27 nucleotides targets that was not only 5-16-folds shorter than the existing PCR-template used in species authentication but also comparable to the size of PCR primers [23-32]. Thus, the higher stability and availability of the targets in extensively autoclaved meat mixtures was not surprising but can be inferred to the natural outcomes. Comparing the corresponding fluorescence of raw (Figure 4) and autoclaved (Figure 5) pork-beef binary admixtures demonstrated $\sim 30 \%$ decreased fluorescence after autoclaving treatment implicating breaking down of a fraction $(\sim 1 / 3)$ of even small targets. This is also reflected by a lower LOD (1\%) of autoclaved meat mixtures than that of raw counterpart $(0.5 \%)$.

Not only the longer DNA-template, the unusually high 


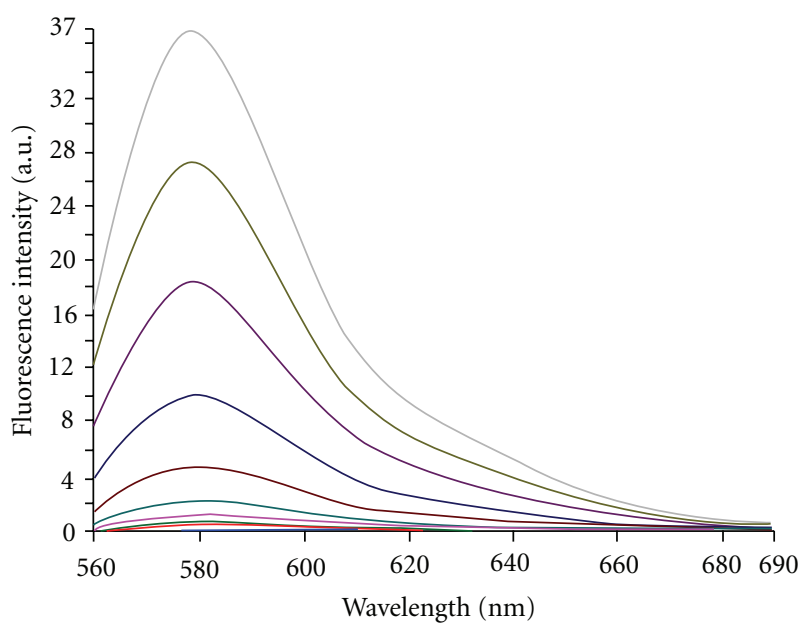

Figure 4: Pork detection in raw pork-beef binary admixtures by porcine-specific nanobiosensor probes. From top to bottom are $100: 0,50: 50,25: 75,10: 90,5: 95,1: 99,0.5: 99.5,0.1: 99.9$, $1,0: 100$, and $0: 0$ (free biosensor probes) pork-beef mixtures. The mixed and pure DNAs extracted from raw meat mixtures were digested with AluI for $8 \mathrm{hrs}$, incubated with porcine-specific nanoconjugate probes for $60 \mathrm{~min}$ and finally the emission spectra were collected at $545 \mathrm{~nm}$ excitation. The final concentration of probes and targets were $10 \mathrm{nM}$ and $60 \mu \mathrm{g} / \mathrm{mL}$. The LOD was found at $0.5 \%$ pork in pork-beef binary admixture and is represented by the pink curve ( 7 th from the top).

prices of real-time PCR instrument, mastermix, and TaqMan probe should be considered for applications of quantitative PCR (qPCR) in developing and underdeveloped countries. Moreover, the recent reports on fake and spurious results of qPCR have considerably clouded the reliability and prospects of this technique in important clinical investigations and food analyses [33]. The conventional PCR-cum electrophoresis is comparatively affordable and reliable. However, it is time consuming and cannot differentiate the sequences with the same molecular sizes. The hazards of using ethidium bromide in electrophoresis detection also demands special precaution. Conventional PCR also cannot quantify the targets in pure or mixed samples.

The method we developed here successfully detected $1 \%$ pork in 2.5-h autoclaved meat mixtures where longer PCRtargets are often broken down using simple instrument and low-cost materials. Citrate-tannate-coated GNPs can be easily prepared and also commercially available at reasonable prices. Although the LOD was lower than that of published results of real-time PCR [29], the assay could find application to analyze processed commercial meat products with considerable pork adulteration where PCR-detection cannot be performed due to the scarcity of longer template caused by degradative processing treatments. Additional, less than $1 \%$ pork adulteration is not commercially viable for making significant profit against high risk of being banned by controlling agency.

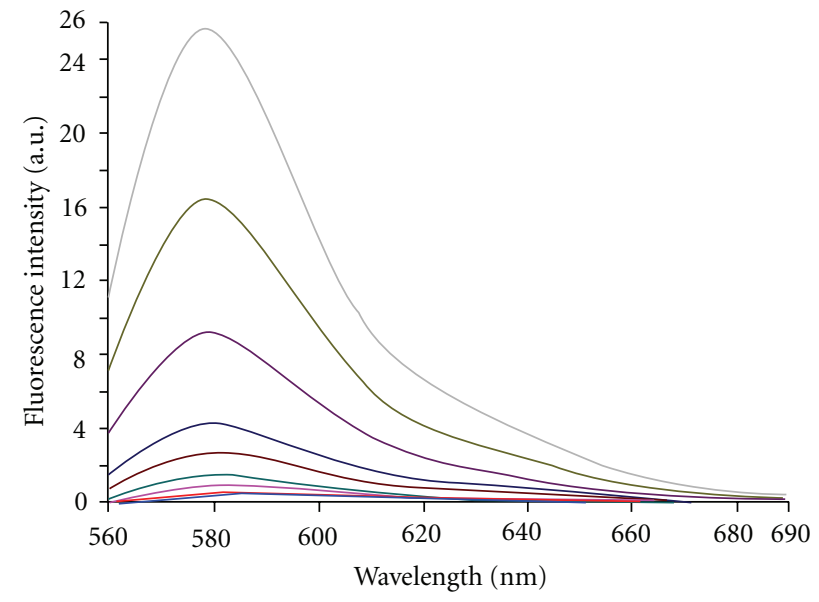

FIGURE 5: Pork detection in autoclaved pork-beef binary admixtures by porcine-specific nanobiosensor probes. From top to bottom are $100: 0,50: 50,25: 75,10: 90,5: 95,1: 99,0.5: 99.5,0.1: 99.9$, $1,0: 100$, and $0: 0$ (free biosensor probes) pork-beef mixtures. The mixed and pure DNAs extracted from 2.5-h autoclaved meat mixtures were digested with AluI for $8 \mathrm{hrs}$, incubated with porcinespecific nanoconjugate probes for $60 \mathrm{~min}$ and finally the emission spectra were collected at $545 \mathrm{~nm}$ excitation. The final concentration of probes and targets were $10 \mathrm{nM}$ and $60 \mu \mathrm{g} / \mathrm{mL}$. The LOD was found at $1 \%$ pork in autoclaved pork-beef binary admixture and is represented by the sky-blue curve (6th from the top).

3.7. Hybridization Kinetics. At a constant concentration of nanoparticle probes $(10 \mathrm{nM})$, a plot of target ssDNA concentration against fluorescence intensity at $579 \mathrm{~nm}$ produced hyperbolic curve (not shown), which was similar to the Michaelis-Menten plot of enzyme kinetics [44]. Like the rate of a typical enzyme catalyzed reaction, fluorescence intensity appeared to be proportional to the target concentration, when the target concentration was low. Like the binding of substrate to the active sites of an enzyme, target ssDNA also bound to the complementary probes, opening the constrained arch-like structure to the rod-like form as shown in Figure 1. The straight-chain structure separated the fluorophore from nanoparticles that quenched the fluorophore when in close proximity. Thus with the increasing target hybridization, fluorescence emission also increased in proportion. However, after 6 -fold increment of targets $(90 \mathrm{nM})$, fluorescence emission reached in a static position. At high concentration of substrate, all the active sites of enzyme are filled with substrate and no substrate can bind further. In the same way, the nanoparticle probes completely hybridized with the complementary targets, resulting in a plateau or ceiling stage of fluorescence. Thus, no probes were left for further hybridization and fluorescence became static. However, at very low target concentration, the change in fluorescence was too small to observe in hyperbolic curve. This can be inferred to the too low collision of probe and targets to bring a detectable change. Therefore, we plotted log of target ssDNA concentration against fluorescence intensity at $579 \mathrm{~nm}$. The curve demonstrated sigmoidal relationship of fluorescence intensities with target concentrations (Figures 6(a) and 6(b)). The sigmoidal relationship can be easily un- 
derstood with the oxygen binding curve of hemoglobin $(\mathrm{Hb})$ or substrate binding curve of allosteric enzymes [44, 45].

Both allosteric enzymes and $\mathrm{Hb}$ are multimeric proteins [44]. They show cooperativity in ligand or substrate binding, that is, binding of the first substrate to one subunit, influences the binding of incoming substrates to other subunits. At a critical concentration of substrates, substrate binding affinity of all subunits significantly increased, dramatically enhancing the rate of reaction. However, at very high concentration of substrate, all subunits become saturated and further addition of substrate does not contribute to the reaction rate. Nanoparticle probes were not multimeric proteins but they might bind more than one oligo-probes to offer multiple hybridization sites for incoming ssDNA targets. As the subunits of allosteric proteins undergoes conformational changes upon substrate binding, the constrained structures of oligo-probes also opened to a relaxed conformation to emit fluorescence $[1,3]$. As the electrical character of ssDNA is different from that of double-stranded DNA [46], the electronic change that is generated upon target hybridization might be transmitted through the highly conductive colloidal gold within the same particle.

The sigmoidal relationship of fluorescence and target concentration can also be explained without considering the behavior of multi-subunit allosteric proteins. Enough collision of probes and targets are necessary for hybridization to take place. To ensure efficient hybridization, Dubertret et al. [3] used 10-fold and Maxwell et al. [1] used 4-fold molar excess of complimentary targets. It is most likely that at very low target concentration $(<1.875 \mathrm{nM}$, probe: target $=8: 1$ shown in circle in Figure 6(a)), target-probe collision was too low to produce effective hybridization to bring a significant change in fluorescence intensity. At an effective concentration of target, hybridization was enough to generate significant change in fluorescence intensity. Thus, the productive concentration of target in the current assay was from $1.875 \mathrm{nM}$ to $90 \mathrm{nM}$. The copy number of nanoparticle probes was calculated assuming that $50 \%$ particles had bound to single oligo-probes and the rest had bound to double oligo-probes according to the protocol described by Maxwell et al. [1]. The copy number of synthetic target was calculated according to the formula given below:

Copy number

$$
=\frac{\text { Amount of DNA } \times \text { Avagrado constant }\left(\mathrm{mol}^{-1}\right)}{\mathrm{MW}},
$$

where Avagrado constant is $6.022 \times 10^{23} \mathrm{~mol}^{-1}$

Thus, the copy number of $10 \mathrm{nM}$ nanoparticle conjugates was $9 \times 10^{12} / \mathrm{mL}$ and $15 \mathrm{nM}$ synthetic target ssDNA was $9.01 \times 10^{12} / \mathrm{mL}$. Thus, we assumed that probe to target ratio was $1: 1$ at $10 \mathrm{nM}$ probes and $15 \mathrm{nM}$ targets (Table S1 in Supplementary Material).

Above 6-fold molar excess of target concentration ( $90 \mathrm{nM}$ shown in circle in Figure 6(a)), the nanobiosensor conjugates saturated with targets and no more hybridization could take place to increase fluorescence emission. Thus, the curve reached in a plateau. However, linearity $\left(R^{2}=0.995\right)$ was found between $3: 1$ and $1: 3$ ratios of probe to target (shown in blue circles and also in the inset). Quantification of pork within this range was found over $90 \%$ accurate.

\subsection{Pork Quantitation in Pure and Mixed Biological Samples.} For quantitation of raw pork, standard curves were generated by plotting the synthetic targets (Figure 6(a)) and the AluI digested raw-pork DNA (Figure 6(b)) against measured fluorescence intensity. Both curves appeared to be very similar in size and shape. It was found that $15 \mathrm{nM}$ synthetic oligo-target containing $9.01 \times 10^{12}$ copies $/ \mathrm{mL}$ produced $20 \pm$ 2 units (arbitrary units) of fluorescence with $10 \mathrm{nM}$ porcine nanobiosensor probes containing equivalent number of oligo-probes (Table S1 in Supplementary Material). Thus, it was assumed that AluI digested porcine targets that would generate fluorescence close to 20 units should contain equivalent copies of cytb genes. It was observed in triplicate experiments that $15 \mu \mathrm{g} / \mathrm{mL}$ porcine DNA digested with AluI produced $19.5 \pm 1$ units of fluorescence upon hybridization with $10 \mathrm{nM}$ porcine nanobiosensor probes (Table S2 in Supplementary Material). Taking average fluorescence (19.53 units), it was calculated that $15 \mu \mathrm{g} / \mathrm{mL}$ AluI digested porcine DNA extracted from raw pork contained $8.57 \times 10^{12}$ copies of cytb genes with a probe to target ratio of $1.05: 1$. Thus, $15 \mu \mathrm{g} / \mathrm{mL}$ AluI digested porcine DNA and 19.53 units of fluorescence were used as internal standard to quantify target DNA and count copy number. Again, the linear relationship was found between fluorescence and target concentration in the range of $3.2: 1$ and $1: 3$ probes to targets ratios. The calculation of relative accuracy using internal standard (Table S2 in Supplementary Material) showed $90-95 \%$ accuracy in the range of $4: 1$ and $1: 4$ probes to target ratios. Beyond this range of probe to target concentrations, quantification was not valid as internal accuracy was too low to accept. However, detection with target that produced more than 1 unit of fluorescence was accepted on the grounds that background fluorescence without any target or with noncomplementary target was always found below 1 unit. Thus the limit of detection (LOD) of synthetic target was at $58.6 \mathrm{pM}$ with 1.163 units fluorescence and probe to target ratio of $256: 1$. Similarly, LOD of pure raw pork target DNA digested with AluI was found at $234 \mathrm{ng} / \mathrm{mL}$ with 1.24 units of emitted fluorescence and a probe to target ratio of $156: 1$. The cause of relatively higher LOD with raw pork can be inferred to incomplete AluI digestion or crowding effect of noncomplementary DNA present in the raw samples.

For quantitation of pork in raw and autoclaved pork-beef binary admixtures, the average fluorescence intensity of triplicate readings (Table S3 \& S4 in Supplementary Material) of the AluI digested DNA mixtures was plotted in the standard curve (Figures 7(a) and 7(b)). The corresponding DNA concentration was obtained from $x$-axis intersects as well as calculated using the equation given in Section 3.1. Unknown pork DNA was determined with $90-97 \%$ accuracy in the range of $1-100 \%$ pork in raw pork-beef admixtures (Table S3 in Supplementary Material). However, $80-90 \%$ accuracy was obtained in the range of $5-100 \%$ pork in $2.5-\mathrm{h}$ autoclaved 


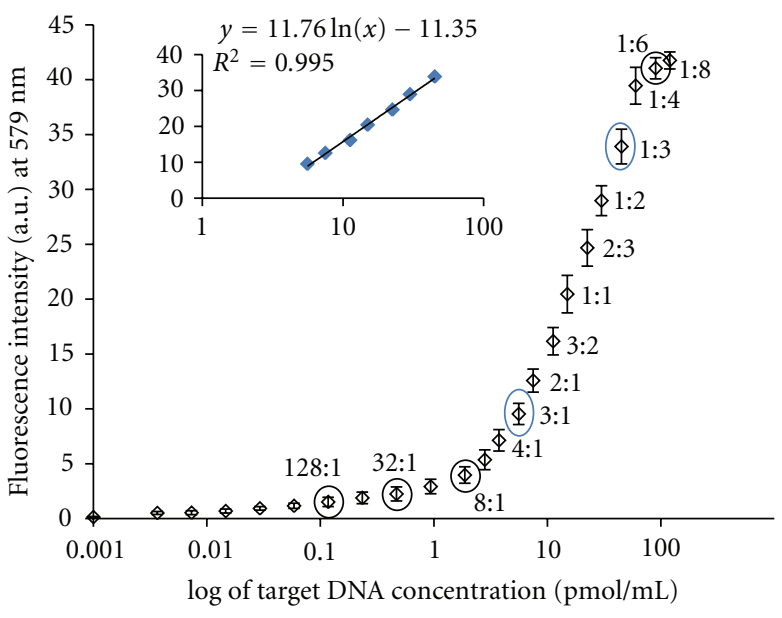

(a)

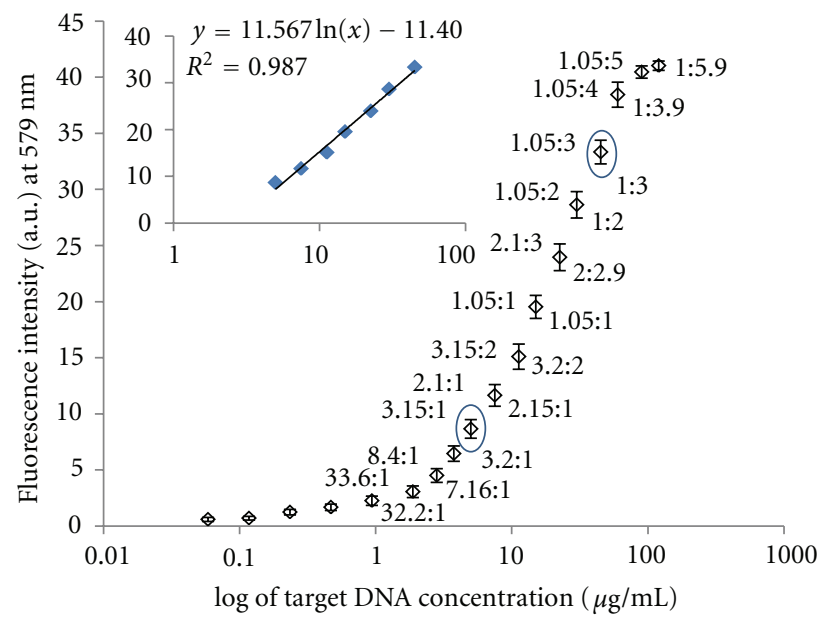

(b)

FIGURE 6: Standard curves of the hybridization kinetics of swine nanobiosensor probes with synthetic (a) and AluI digested swine DNA extracted from raw-pork (b). The linear parts of the curves are represented by blue circles and also shown in the insets. The calculated and estimated probe/target ratios are shown on the left and right sides of each point (right curves). The probe/target ratios calculated from used synthetic targets are shown in the left curve. The final concentration of porcine nanoparticle probe was $10 \mathrm{nM}$ in both cases with $9.01 \times$ $10^{12}$ nanoparticles $/ \mathrm{mL}$. The copy number was calculated assuming 1.5 oligos/particle (50\% particles bound to 2 -oligo probes \& $50 \%$ bound to 1-oligo probe). Each point was an average of three readings. The standard deviations at each point are shown in error bars. Note that quantitation is not valid at too low or too high concentration of target DNA.

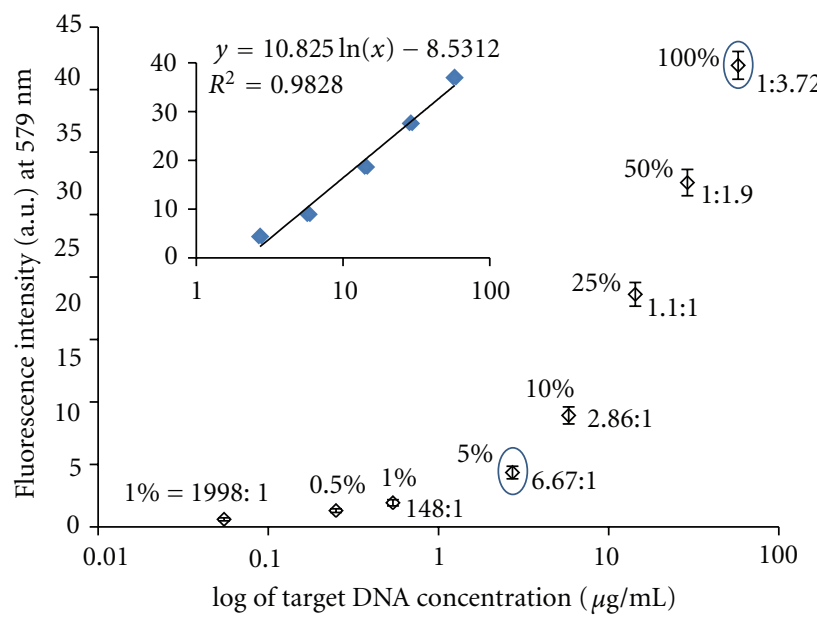

(a)

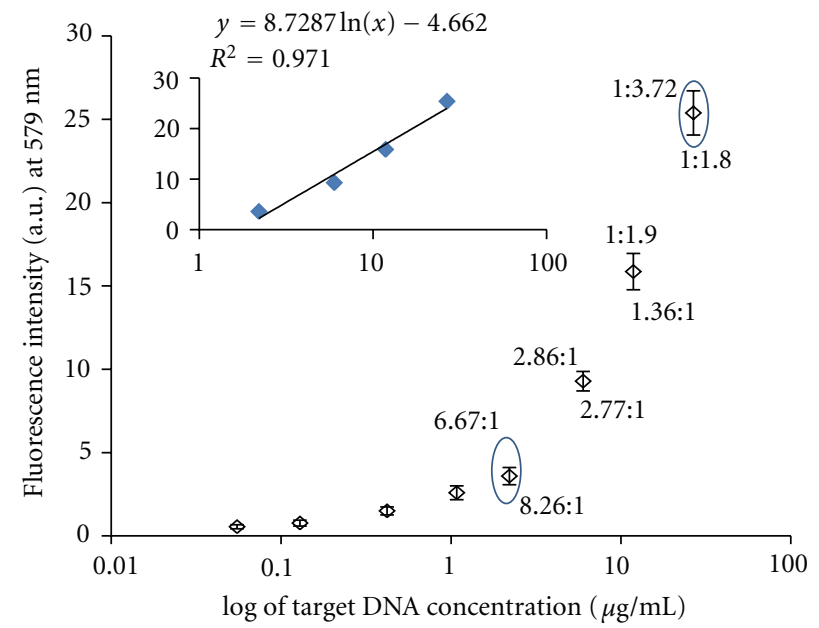

(b)

FIGURE 7: Determination of pork in raw (a) autoclaved (b) pork-beef binary admixtures by porcine-specific nanobiosensor probes. Approximate ratios of probes to targets at various percentage of pork in raw-pork beef mixtures are shown in (a). The expected and estimated probe/target ratios in autoclaved mixed meat samples are shown on the left and right sides of each point in (b). Each point is an average of three readings. The standard deviations at each point are shown in error bars. Note that quantitation is not valid at too low or too high concentration of target DNA.

pork-beef binary mixtures. Linearity between fluorescence emission and target concentration was obtained from 5$100 \%$ in raw mixture and $10-100 \%$ pork in autoclaved mixtures with $R^{2}$ value 0.982 and 0.971 , respectively. Moreover, approximately $30 \%$ reduction of corresponding fluorescence was observed with heat-pressurized (autoclaved) mixed meat sample indicating considerable degradation of even small size (27nucleotide) target DNA. We would like to remind the readers that Rodriguez's PCR assay [29] failed to detect any pork target even in $100 \%$ pork autoclaved under identical conditions (Figure S3 in Supplementary Material). Very high gap between the estimated and calculated (expected) probe to target ratios at the very low target concentration $(<420 \mathrm{ng} / \mathrm{mL}=1 \%$, Table S4 in Supplementary Material $)$ in autoclaved mixed meats further supported that quantifi- 
cation was not accurate at extreme target concentrations. Figure 7 further demonstrated that the plateau portion of the standard curve (Figure 6) was not obtained in quantification curve because 1:3.7 (Figure 6(a)) and 1:1.8 (Figure 6(b)) probes to targets ratios were not enough to saturate the probes to bring the fluorescence emission in a static position.

Counting the copy number of mitochondrial genes was not straight forward. First, number of mitochondria varies from tissue to tissues, second, number of mitochondrial genes varies from species to species, and, third, evolution rates of mitochondrial genes are very high [47]. Thus, the exact copy number of mitochondrial genes was unknown. Except real-time PCR and DNA-microarray, we do not know any methods for calculating copy number. The method developed in the current assay for copy number calculation was much simpler, convenient, and cheaper than the existing ones.

\section{Conclusion}

The current assay developed swine nanobiosensor for detection, quantification, and copy number calculation of pork DNA in heat processed mixed-meat products. The assay was a very simplified and straight forward approach that did not need any purification and separation steps as well as any expensive instrumentation and reagents for solving a very big issue such a target DNA quantification and copy number calculation in mixed biological samples as well as genetic screening in clinical diagnosis. The developed biosensors detected as low as $1 \%$ pork in mixed meats cooked under heat and pressure for 2.5-h that extensively degraded longer DNA targets causing failure of PCR-based identification methods. Although the LOD of the assay was higher than that of the qPCR, the higher stability of the shorter targets than the longer PCR template made it applicable where PCR-based detection cannot be applied due to template scarcity. The quantification scheme of the developed method was not valid at extreme target concentrations. However, the assay was fairly accurate over a range of moderate concentration of DNA targets. The assay was a viable alternative approach of qPCR for detecting, quantifying, and calculating copy number of shorter size DNA sequences in degraded samples to address a range of biological problems such as food analysis, biodiagnostics, environmental monitoring, and genetic screening.

\section{Acknowledgments}

This Research was supported by Grants "RUGS No. 9031" to Prof. Y. B. Che Man, "MOSTI no. 05-01-35-SF-1030” to Prof. U. Hashim, and UniMAP Graduate Fellowship to M. E. Ali.

\section{References}

[1] D. J. Maxwell, J. R. Taylor, and S. Nie, "Self-assembled nanoparticle probes for recognition and detection of biomolecules," Journal of the American Chemical Society, vol. 124, no. 32, pp. 9606-9612, 2002.

[2] D. Gerion, W. J. Parak, S. C. Williams, D. Zanchet, C. M. Micheel, and A. P. Alivisatos, "Sorting fluorescent nanocrystals with DNA," Journal of the American Chemical Society, vol. 124, no. 24, pp. 7070-7074, 2002.

[3] B. Dubertret, M. Calame, and A. J. Libchaber, "Single-mismatch detection using gold -quenched fluorescent oligonucleotides," Nature Biotechnology, vol. 19, no. 4, pp. 365-370, 2001.

[4] K. Sato, K. Hosokawa, and M. Maeda, "Rapid aggregation of gold nanoparticles induced by non-cross-linking DNA hybridization," Journal of the American Chemical Society, vol. 125, no. 27, pp. 8102-8103, 2003.

[5] B. S. Gaylord, A. J. Heeger, and G. C. Bazan, "DNA hybridization detection with water-soluble conjugated polymers and chromophore-labeled single-stranded DNA," Journal of the American Chemical Society, vol. 125, no. 4, pp. 896-900, 2003.

[6] A. Henglein, "Small-particle research: physicochemical properties of extremely small colloidal metal and semiconductor particles," Chemical Reviews, vol. 89, no. 8, pp. 1861-1873, 1989.

[7] G. Schmid, "Large clusters and colloids. Metals in the embryonic state," Chemical Reviews, vol. 92, no. 8, pp. 1709-1727, 1992.

[8] A. P. Alivisatos, "Semiconductor clusters, nanocrystals, and quantum dots," Science, vol. 271, no. 5251, pp. 933-937, 1996.

[9] S. R. Nicewarner-Peña, R. G. Freeman, B. D. Reiss et al., "Submicrometer metallic barcodes," Science, vol. 294, no. 5540, pp. 137-141, 2001.

[10] M. Han, X. Gao, J. Z. Su, and S. Nie, "Quantum-dot-tagged microbeads for multiplexed optical coding of biomolecules," Nature Biotechnology, vol. 19, no. 7, pp. 631-635, 2001.

[11] C. A. Mirkin, R. L. Letsinger, R. C. Mucic, and J. J. Storhoff, "A DNA-based method for rationally assembling nanoparticles into macroscopic materials," Nature, vol. 382, no. 6592, pp. 607-609, 1996.

[12] A. P. Alivisatos, K. P. Johnsson, X. Peng et al., "Organization of 'nanocrystal molecules' using DNA," Nature, vol. 382, no. 6592, pp. 609-611, 1996.

[13] J. J. Storhoff, A. A. Lazarides, R. C. Mucic, C. A. Mirkin, R. L. Letsinger, and G. C. Schatz, "What controls the optical properties of DNA-linked gold nanoparticle assemblies?" Journal of the American Chemical Society, vol. 122, no. 19, pp. 4640-4650, 2000.

[14] H. Mattoussi, J. Matthew Mauro, E. R. Goldman et al., "Selfassembly of CdSe-ZnS quantum dot bioconjugates using an engineered recombinant protein," Journal of the American Chemical Society, vol. 122, no. 49, pp. 12142-12150, 2000.

[15] M. A. El-Sayed, "Some interesting properties of metals confined in time and nanometer space of different shapes," Accounts of Chemical Research, vol. 34, no. 4, pp. 257-264, 2001.

[16] P. Mitchell, "Turning the spotlight on cellular imaging," $\mathrm{Na}$ ture Biotechnology, vol. 19, no. 11, pp. 1013-1017, 2001.

[17] L. Josephson, C. H. Tung, A. Moore, and R. Weissleder, "Highefficiency intracellular magnetic labeling with novel superparamagnetic-tat peptide conjugates," Bioconjugate Chemistry, vol. 10, no. 2, pp. 186-191, 1999.

[18] J. W. M. Bulte, T. Douglas, B. Witwer et al., "Magnetodendrimers allow endosomal magnetic labeling and in vivo tracking of stem cells," Nature Biotechnology, vol. 19, no. 12, pp. 1141-1147, 2001.

[19] A. Curtis and C. Wilkinson, "Nantotechniques and approaches in biotechnology," Trends in Biotechnology, vol. 19, no. 3, pp. 97-101, 2001.

[20] R. Gref, Y. Minamitake, M. T. Peracchia, V. Trubetskoy, V. Torchilin, and R. Langer, "Biodegradable long-circulating pol- 
ymeric nanospheres," Science, vol. 263, no. 5153, pp. 16001603, 1994.

[21] S. Tyagi and F. R. Kramer, "Molecular beacons: probes that fluoresce upon hybridization," Nature Biotechnology, vol. 14, no. 3, pp. 303-308, 1996.

[22] S. Tyagi, D. P. Bratu, and F. R. Kramer, "Multicolor molecular beacons for allele discrimination," Nature Biotechnology, vol. 16, no. 1, pp. 49-53, 1998.

[23] A. Ardura, I. G. Pola, I. Ginuino, V. Gomes, and E. GarciaVazquez, "Application of barcoding to Amazonian commercial fish labelling," Food Research International, vol. 43, no. 5, pp. 1549-1552, 2010.

[24] N. Z. Ballin, F. K. Vogensen, and A. H. Karlsson, "Species determination-can we detect and quantify meat adulteration?" Meat Science, vol. 83, no. 2, pp. 165-174, 2009.

[25] Y. B. Che Man, A. A. Aida, A. R. Raha, and R. Son, "Identification of pork derivatives in food products by species-specific polymerase chain reaction (PCR) for halal verification," Food Control, vol. 18, no. 7, pp. 885-889, 2007.

[26] A. Arslan, O. I. Ilhak, and M. Calicioglu, "Effect of method of cooking on identification of heat processed beef using polymerase chain reaction (PCR) technique," Meat Science, vol. 72, no. 2, pp. 326-330, 2006.

[27] A. K. Lockley and R. G. Bardsley, "DNA-based methods for food authentication," Trends in Food Science and Technology, vol. 11, no. 2, pp. 67-77, 2000.

[28] I. Martinez and I. Malmheden Yman, "Species identification in meat products by RAPD analysis," Food Research International, vol. 31, no. 6-7, pp. 459-466, 1998.

[29] M. A. Rodríguez, T. García, I. González, P. E. Hernández, and R. Martín, "TaqMan real-time PCR for the detection and quantitation of pork in meat mixtures," Meat Science, vol. 70, no. 1, pp. 113-120, 2005.

[30] E. H. K. Wong and R. H. Hanner, "DNA barcoding detects market substitution in North American seafood," Food Research International, vol. 41, no. 8, pp. 828-837, 2008.

[31] T. Matsunaga, K. Chikuni, R. Tanabe et al., "A quick and simple method for the identification of meat species and meat products by PCR assay," Meat Science, vol. 51, no. 2, pp. 143148, 1999.

[32] J. R. Lin, H. Zhou, X. P. Lai et al., "Genetic identification of edible birds' nest based on mitochondrial DNA sequences," Food Research International, vol. 42, no. 8, pp. 1053-1061, 2009.

[33] S. A. Bustin, V. Benes, J. A. Garson et al., "The MIQE guidelines: minimum information for publication of quantitative real-time PCR experiments," Clinical Chemistry, vol. 55, no. 4, pp. 611-622, 2009.

[34] "Preparing colloidal gold for electron microscopy," Polyscience Inc., Technical data sheet 787, 2009.

[35] W. Haiss, N. T. K. Thanh, J. Aveyard, and D. G. Fernig, "Determination of size and concentration of gold nanoparticles from UV-Vis spectra," Analytical Chemistry, vol. 79, no. 11, pp. 4215-4221, 2007.

[36] "Using UV-vis as a tool to determine size and concentration of spherical gold nanoparticles (SGNPs)," Nanopartz, Technical note 801, 2008, http://www.nanopartz.com.

[37] LA. O. Srisombat, J. S. Park, S. Zhang, and T. R. Lee, "Preparation, characterization, and chemical stability of gold nanoparticles coated with mono-, bis-, and tris-chelating alkanethiols," Langmuir, vol. 24, no. 15, pp. 7750-7754, 2008.

[38] C. Jung, H. Y. Mun, T. Li, and H. G. Park, "A simple gold nanoparticle-mediated immobilization method to fabricate highly homogeneous DNA microarrays having higher capacities than those prepared by using conventional techniques," Nanotechnology, vol. 20, no. 3, Article ID 035607, 2009.

[39] L. M. Demers, C. A. Mirkin, R. C. Mucic et al., "A fluorescentbased methods for determination of surface coverage and hybridization efficiency of thiol-capped oligonucleotides bound to gold thin films and nanoparticles," Analytical Chemistry, vol. 72, pp. 5535-5541, 2000.

[40] S. F. Liu, Y. F. Li, J. R. Li, and L. Jiang, "Enhancement of DNA immobilization and hybridization on gold electrode modified by nanogold aggregates," Biosensors and Bioelectronics, vol. 21, no. 5, pp. 789-795, 2005.

[41] M. O. Nutt, K. N. Heck, P. Alvarez, and M. S. Wong, "Improved Pd-on-Au bimetallic nanoparticle catalysts for aqueous-phase trichloroethene hydrodechlorination," Applied Catalysis B, vol. 69, no. 1-2, pp. 115-125, 2006.

[42] P. Hildebrandt and M. Stockhurger, "Surface-enhanced resonance raman spectroscopy of rhodamine $6 \mathrm{G}$ adsorbed on colloidal silver," Journal of Physical Chemistry, vol. 88, no. 24, pp. 5935-5944, 1984.

[43] M. E. Ali, U. Hashim, S. Mustafa et al., "Nanoparticle sensor for label free detection of swine DNA in mixed biological samples," Nanotechnology, vol. 22, no. 19, Article ID 195503, 2011.

[44] J. M. Berg, E. L. Tymoczko, and L. Stryer, Biochemistry, W. H. Freeman, New York, NY, USA, 5th edition, 2002.

[45] W. F. Ganong, Review on Medical Physiology, Appleton \& Lange, Norwalk, Conn, USA, 16th edition, 1993.

[46] T. G. Drummond, M. G. Hill, and J. K. Barton, "Electrochemical DNA sensors," Nature Biotechnology, vol. 21, no. 10, pp. 1192-1199, 2003.

[47] C. Murugaiah, Z. M. Noor, M. Mastakim, L. M. Bilung, J. Selamat, and S. Radu, "Meat species identification and Halal authentication analysis using mitochondrial DNA," Meat Science, vol. 83, no. 1, pp. 57-61, 2009. 

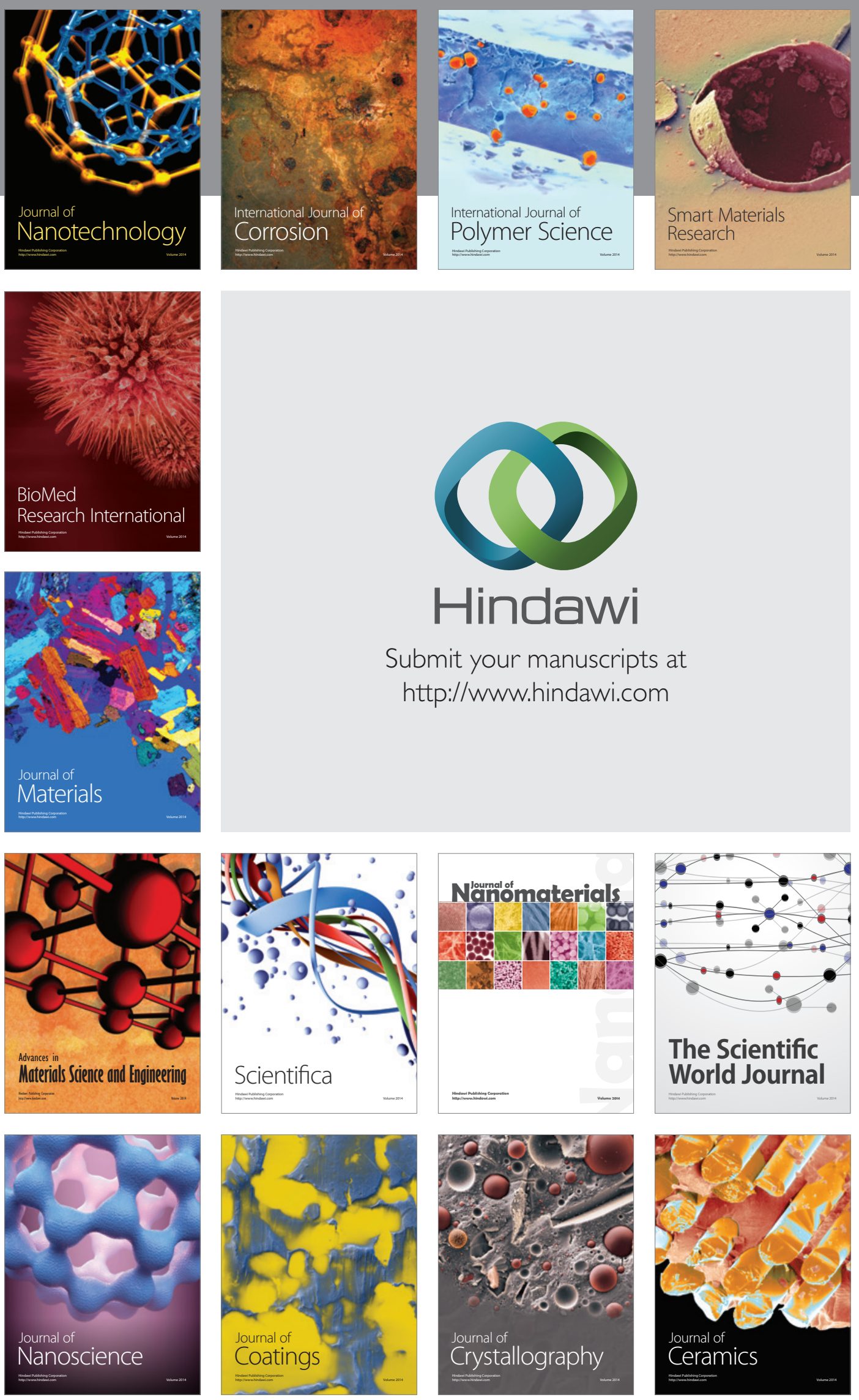

The Scientific World Journal

Submit your manuscripts at

http://www.hindawi.com

\section{World Journal}

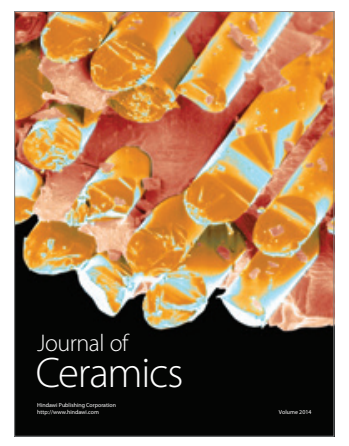

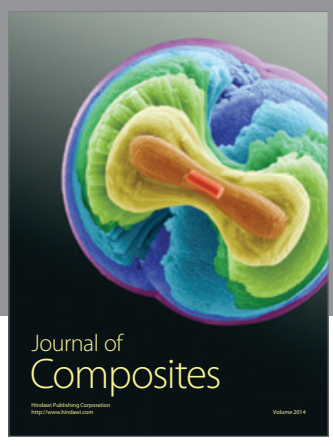
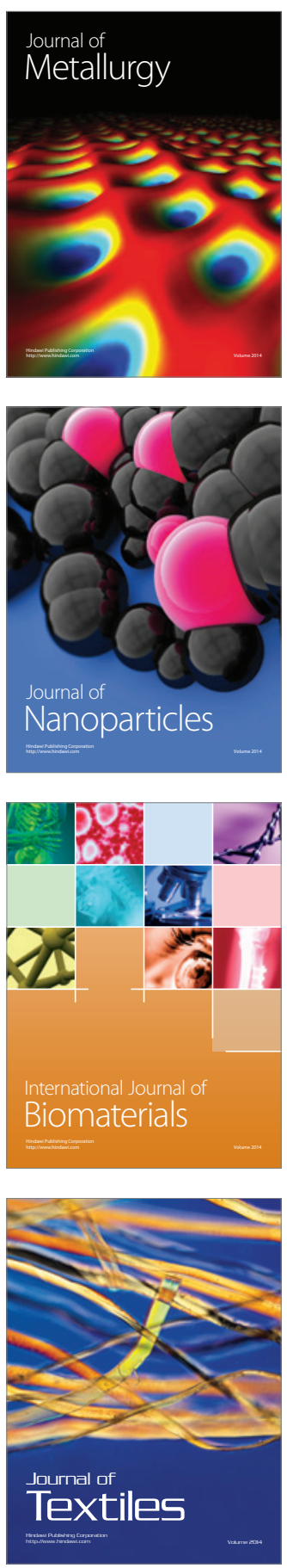